2017-10-16

\title{
Trait emotional intelligence and social deviance in males and females
}

\section{Bacon, Alison}

http://hdl.handle.net/10026.1/10051

10.1016/j.paid.2017.10.015

Personality and Individual Differences

Elsevier

All content in PEARL is protected by copyright law. Author manuscripts are made available in accordance with publisher policies. Please cite only the published version using the details provided on the item record or document. In the absence of an open licence (e.g. Creative Commons), permissions for further reuse of content should be sought from the publisher or author. 
Running head: TRAIT EI AND DEVIANT BEHAVIOUR

Authors' copy of paper to be published in Personality

\& Individual Differences.

This is not the copy of record.

Trait emotional intelligence and social deviance in males and females

Alison M. Bacon, Lindsay Lenton-Maughan \& Jon May

School of Psychology

University of Plymouth, UK

Corresponding author:

Dr Alison M. Bacon

School of Psychology

Plymouth University

Drake Circus

Plymouth PL4 8AA

Tel: 01752584805

Fax: 01752584808

Email: ambacon@plymouth.ac.uk 


\begin{abstract}
High trait Emotional Intelligence (trait EI) is often considered a positive attribute, but some studies have suggested that it may facilitate deception or manipulative relational behaviours, and that the effects differ according to gender. In two studies, we examine the influence of trait EI factors on social deviance, from adolescence through to adulthood. A total of 455 participants (243 females) completed the Trait EI Questionnaire and provided self-reports of deviant behaviours during adolescence and emerging adulthood (Study 1) or in adulthood (Study 2). For males, adolescent and emerging adult deviance related negatively to Emotionality and Self-control, in accordance with positive views of trait EI, but in adulthood deviance was predicted only by high Sociability. For females, the opposite pattern was seen, with high levels of Emotionality and Sociability associated with deviance in adolescence and high Sociability in emerging adulthood. Adult female social deviance was negatively correlated with Self-control and Emotionality, replicating the adolescent male profile. Trait EI is not inevitably positive, and is an under-researched personality determinant of social deviance. Further consideration of the developmental trajectory of trait EI may provide insights to inform intervention with at-risk individuals in adolescence, and beyond.
\end{abstract}

Keywords: trait emotional intelligence; antisocial behaviour; social deviance; gender differences; emerging adulthood, adolescence, TEI-Que 
Running head: TRAIT EI AND DEVIANT BEHAVIOUR

and self-perceptions which together reflect the ability to identify, attend to, experience, understand and utilise emotions (Petrides, 2009; Petrides \& Furnham, 2003; Petrides, Pita \& Kokkinaki, 2007). Trait EI integrates affective aspects of personality in terms of four factors: Wellbeing (high scorers feel, content, confident and fulfilled), Sociability (high scorers feel agentic in social contexts and have good interpersonal skills); Self-control (high scorers are good at controlling urges and desires, regulating external pressures and handling stress) and Emotionality (high scorers understand their own and others' feelings and can use this ability in sustaining relationships with others; Petrides et al, 2007; Petrides, 2009; Petrides, Mikolajczak, Mavroveli, Sanchez-Ruiz, Furnham \& Perez-Gonzales, 2016). Although correlated with other higher-order personality dimensions trait EI is distinct in personality factor space, showing clear incremental validity over models of personality such as the Big Five and Giant Three (e.g. Petrides, et al, 2007; Pérez-González \& Sanchez-Ruiz, 2014). Higher levels of trait EI are generally considered adaptive and are found to predict superior workplace performance (O’Boyle, Humphrey, Pollack, Hawver, \& Story, 2011; Wong \& Law, 2002), mental and physical health (Austin, Saklofske \& Egan, 2005; Schutte, Malouff, Thorsteinsson, Bhullar, \& Rooke, 2007), social relationships (Mavroveli, Petrides, Rieffe, \& Bakker, 2007), educational achievement and fewer unauthorized absences and school exclusions (Petrides, Frederickson and Furnham, 2004).

In defining the construct, it is important to note the distinction between trait EI, as assessed by self-report, and ability EI which is measured by maximum performance tests in a similar way to intelligence (Petrides, Pita, \& Kokkinaki, 2007). While both emphasise managing and understanding emotions, the conceptual differences between the two are reflected in empirical data which has shown very low correlations between measures of the two constructs (O’Connor \& Little, 2003; Warwick \& Nettelbeck, 2004). A review by 
Running head: TRAIT EI AND DEVIANT BEHAVIOUR

Zeidner, Matthews and Roberts (2012) has indicated that self-report measures of EI appear to be more robustly related to health and well-being criteria than are ability-based measures and the present studies are concerned with this trait EI approach.

In the present studies, we are interested in the relationship between individual differences in trait EI and socially deviant behaviour. For this purpose, we define social deviance in terms of the description of antisocial behaviour offered by Rutter (2003) who suggested that it be characterized as nonconformity, disregard or unwillingness to adhere to rules and obligations imposed by society or social organizations. As such, it may include criminal acts which violate specific laws, but also behaviours which are not in themselves illegal but which contradict the social norms of the culture in which the individual resides, for instance, cheating in exams bullying and name-calling can be classed as antisocial by this definition. As such, occurrence of deviant behaviour is not the sole preserve of forensic samples and can be measured within a general population. It is notable that thrust of antisocial behaviour legislation in the UK over the last two decades has been aimed at deviant, non-criminal behaviours. For instance, the Antisocial Behaviour Order and subsequent Antisocial Behaviour Injunction legislation was designed to address activities such as drunken or threatening behaviour, vandalism, graffiti or playing loud music at night using civil orders rather than criminal sanctions (Home Office, 2014). Socially deviant behaviours have been associated with low scores on measures of a number of emotional personality factors including emotional and behavioural self-regulation (Downey, Johnston, Hansen, Birney, \& Stough, 2010 (Eisenberg et al. 1996; Moffitt et al., 2011), empathy (Jolliffe \& Farrington, 2007; Marshall \& Marshall, 2011; Milojević \& Dimitrijević, 2014) as well as poor mentalisation (Fonagy et al., 1997) impulsivity and sensation seeking (Gomà-iFreixanet, 1995; Romero, Luengo, \& Sobral, 2001). Unsurprisingly therefore, low trait EI is 


\section{Running head: TRAIT EI AND DEVIANT BEHAVIOUR}

also claimed to be a risk factor for various maladaptive behaviours, including those considered deviant or antisocial (Zeidner, Matthews, \& Roberts, 2009), including bullying (Kokkinos \& Kipritsi, 2012) and aggressive behaviour in adolescents (Gugliandolo, Costa, Cuzzocrea, Larcan, \& Petrides, 2015).

Furthermore, there is a growing body of evidence suggesting a darker side to trait EI and several studies have suggested that it may be used as a tool for deception or manipulative relational behaviours and that the effects differ according to gender. Grieve and Panebianco (2013) reported that male participants with higher levels of trait EI, social information processing, indirect aggression, and self-serving cognitive distortions were more likely to exploit others. Jones and Paulhus (2011) suggested that good interpersonal skills are necessary in order to successfully manipulate others: without understanding others' emotions and being able to influence them, manipulative individuals would simply not be able to achieve their goals. As well as such interpersonal talents facilitating the manipulation of others, an added advantage is the ability to behave in such a socially skilled manner that the aggressor can appear innocent of any wrongdoing or harmful intention (Björkqvist, 1994). Hence the desired goal is attained without attribution of blame, and therefore at no cost to the perpetrator.

In one of the few studies to consider gender-differences in the relationship between socially deviant behaviors and trait EI, Bacon, Burak and Rann (2014) collected self-reports of adolescent delinquency in a young student population aged $18-25$. They found that male participants with higher global trait EI scores reported lower levels of delinquency, however, high trait EI females reported higher levels of delinquency. These results were interpreted as reflecting the protective influence of self-regulation (emotional and behavioural) and low impulsivity in males, while for females, Bacon et al (2014) postulated 
Running head: TRAIT EI AND DEVIANT BEHAVIOUR

that an understanding of others peoples' emotions facilitates emotionally manipulative behaviors and relational aggression. Such deviant, but not criminal, behaviours are known to be prevalent amongst adolescent females, as opposed to males where physically aggressive behaviour is more common (Archer, 2004; Björkqvist, 1994; Österman et al., 1998; Viding, Simmonds, Petrides, \& Frederickson, 2009). Most recently, Bacon and Regan (2016) showed that high trait EI females who report deviant behaviours also score highly on aspects of emotional manipulation, assessed with the Manipulating the Emotions of Others Scale (Austin \& O’Donnell, 2013) and also on Machiavellianism, a personality trait typified by deceptive and manipulative social behaviours (Christie \& Geis, 1970).

However, a major limitation of this work is that it is focusses only on global trait EI scores. As trait EI is a multidimensional construct, analysis at its global level cannot fully encapsulate potential variation in emotional perceptions and may mask differential relationships between the trait EI facets and other criteria of interest (Petrides et al, 2016). For instance, Zeidner et al (2012) review research which has suggested that it is the emotional understanding and regulation aspects of EI specifically that protect against addiction, a key factor in many acts of deviance. A recent study (Milojević, Dimitrijević, Marjanović \& Dimitrijević, 2016) compared trait EI scores in a sample of convicted juvenile delinquents and a non-forensic sample. They found that the delinquents showed lower scores on the Emotionality, Well-being and Self-control trait EI factors. Research using ability EI measures have found similar results (Brackett, Mayer \& Warner, 2004; Hayes \& Reilly, 2013). These results explicate Bacon et al's (2014) findings for males but do not consider female antisocial behaviour.

Our Study 1 addresses these issues in a replication of Bacon et al (2014) where we 
Running head: TRAIT EI AND DEVIANT BEHAVIOUR

examine retrospective reports of adolescent deviant behaviour (between ages 12 and 18) but using a full-scale trait EI measure that allowed for the examination of scores on the four subfactors, rather than simply the global score. The first aim of Study 1 therefore was to test Bacon et al's (2014) proposal that a positive relationship between trait EI and adolescent deviance in young females reflects a malignant and self-serving utilisation of emotional understanding and, conversely, that the suggested protective effect of high trait EI in young males reflects low impulsivity and high self-regulation. In terms of the four sub-factors of trait EI, if Bacon et al's thesis is correct we should observe a negative association between levels of deviant behaviour and Self-control in males and positive association between levels of deviant behaviour and both Emotionality and Sociability in females. However, it is possible that trait EI factors might be differentially implicated in deviant behaviours of different kinds, for instance skiving school compared to a violent assault. As such we developed the methodology in a further way in order to test this possibility, categorising the behaviours into two types according to whether they reflect criminal conduct (behaviours generally associated with juvenile delinquency or criminality, such as vandalism, theft and arson) and behaviours reflecting more mainstream deviance such as exam cheating or verbal bullying.

Furthermore, we extended the line of enquiry by also obtaining reports of more current deviance in emerging adulthood, ages 18-25. Arnett (2000) argues that this stage is distinct from both adolescence and adulthood and is distinguished by relative independence from social roles and normative expectations. Individuals in this stage are no longer fully dependent on their families or carers but have not yet entered into the full responsibilities of adulthood. As such, this lifestage is often typified by exploration of different potential life directions in personal, professional and worldview domains. The few studies which have 
Running head: TRAIT EI AND DEVIANT BEHAVIOUR

considered crime/social deviance in this specific lifestage have tended to focus on social and life circumstances (e.g. Piquero, Brame, Mazerolle, \& Haapanen, 2002) rather than personality traits. As such, the second aim of Study 1 was to examine whether the trait EI profiles observed for socially deviant adolescents remain stable into emerging adulthood.

Study 2 examined the trait EI profile of socially deviant adults. Firstly, we expected that both types of deviant behaviour would be reported at lower levels than in Study 1 as most individuals desist with age. Secondly, we expected that individuals reporting higher levels of deviance would continue to show poor Self-control (males) and Emotionality (females) in terms of trait EI scores. Going beyond Bacon et al.'s (2014) findings, in Study 2 we expand the research into an older non-student population in order to examine trait EI profiles in those committing deviant acts as adults. Whilst for most adolescents, some form of antisocial or deviant behaviour is part of a relatively benign and short-lived episode in the transition to adulthood, Moffitt (e.g. 1993; 2006) has identified a group she terms life-course persistent offenders in whom antisocial behaviour and crime persists into adulthood.

Although Moffitt's account proposes that many of the main determinants of life-course offending are social, she also suggests that such offenders may fail to develop the prosocial and self-regulatory cognitions which contribute to desistance in late adolescence for most individuals. An alternative account, the antisocial propensity theory (Lahey \& Waldman, 2003) argues for a general lifetime developmental trajectory within which three dispositional dimensions in particular (prosociality, daring and negative emotionality) may predispose to offending. Overall, whether or not adolescents can be considered a separate category of offender from those in emerging or full adulthood, these theories suggest that individuals who are reporting deviance beyond adolescence may present deficits in emotional perceptions and behaviours and the present studies investigate this possibility. 


\section{Method}

\section{Participants}

Studyl:

Two hundred and fifty-six undergraduate students aged between 18 and 25 completed the study in return for course credit. The sample comprised 131 females $\left(M_{\text {age }}=20.79, S D=\right.$ $2.19)$ and 125 males $\left(M_{\text {age }}=20.70, S D=2.24 ; p_{a g e}=.75\right)$. Two participants reported being convicted of an offence but none had ever been in prison or youth custody. Selecting participants in this age group not only replicated the methods of Bacon et al (2014), but also allowed for the collection of current self-reports relating to emerging adulthood, and also of adolescent deviancy which, although retrospective, are not too historical.

\section{Study 2:}

One hundred and ninety nine participants aged over 25 were recruited through Prolific Academic, a UK based online research participation website, and paid $£ 3$ for their time. All bar two were educated to at least UK A' Level standard: Males $N=81, M_{a g e}=31.69, S D=$ 4.11; Females $N=118, M_{\text {age }}=31.54, S D=4.28\left(p_{\text {age }}=.81\right)$. No participants reported a conviction though one said they had been incarcerated. Selecting participants in this age group allowed for the methods of Bacon et al (2014) to be extended to an older age group.

All participants, in both studies, had grown up in the UK and none declared having been diagnosed with any psychological disorder.

\section{Materials and procedures}


Running head: TRAIT EI AND DEVIANT BEHAVIOUR

On volunteering to take part, participants were sent a web link to an online survey which, first presented details of the study. Participants were required to check a box giving informed consent after which they completed two measures:

Trait Emotional Intelligence Questionnaire v 1.50 (TEIQue; Petrides, 2009). This 153 item measure yields scores for the four sub-factors of trait EI. Participants respond to each item on a 7 -point scale where $1=$ disagree completely and 7 = agree completely. Reliability was good for all 15 facets in ( $\alpha$ between .73 and .93) and for the four sub-factors on which we have based our analysis $(.78<\alpha<.83)$.

Socially deviant behaviour: This measure was a shortened version of the Delinquent Behaviour Scale employed by Bacon et al (2014). We presented a list of 35 deviant behaviours and participants were asked to respond yes to any they had engaged in. The items ranged from relatively minor criminal offences such as using public transport without a ticket to more serious offences such as physical assault, and non-criminal but deviant behaviours such as cheating in an exam or test or spreading untrue rumours about another person. Participants in Study 1 were asked for two responses to each item, one to indicate whether they had engaged in the activity during adolescence (defined as between 12 and 18 years of age) and secondly whether they had done so in emerging adulthood (within the last 12 months). For Study 2 we asked only for reports of any actions within the previous 12 months. Deviant behaviour scores were obtained by summing yes responses. The scales showed adequate reliability, adolescent $\alpha=.71$; emerging adult $\alpha=.69$, adult $\alpha=.79$. Appendix A presents the questionnaire items and their categorisation into deviant behaviours (DB) and criminal behaviours (CB). 
Running head: TRAIT EI AND DEVIANT BEHAVIOUR

\section{Results}

The upper section of Table 1 shows descriptive statistics for Study 1. Males and females did not differ significantly in the level of criminal behaviour $(\mathrm{CB} ; p=.89)$ or deviant behaviour (DB: $p=.28$ ). In terms of trait EI, males scored most highly on Self-control, $t$ $(254)=2.60, p=.01$, and females on Emotionality, $t(254)=3.63, p<.001$. The lower half of Table 1 presents the adult data for Study 2. The level of both DB and CB are markedly lower than those in either adolescent or emerging adulthood reported in Study 1. Here males reported significantly higher rates than did females: $\mathrm{CB} t(197)=3.53, p<.001$ and DB $t$ $(197)=3.56, p<.001$. Females scored most highly on trait EI factor Emotionality, $t(197)=$ $3.96, p<.001$, though on the other EI factors male and female scores were comparable.

\section{PLEASE INSERT TABLE 1 ABOUT HERE}

Reported levels of CB and DB were positively associated in both studies (females Study $1 r=.62$, Study $2 r=.48$; males Study $1 r=.64$, Study $2 r=.50 ;$ all $p<.001)$. Table 2 presents correlations between the measures. In Study 1, both types of female adolescent deviance are positively related to Emotionality and Sociability as predicted, in contrast to male adolescent $\mathrm{CB}$ which presents no association with trait EI, and DB which shows negative associations with all but Sociability. In terms of behaviours in Emerging Adulthood, males present negative associations between the trait EI factors and both $\mathrm{CB}$ and $\mathrm{DB}$, but females show no association between either form of behaviour and trait EI with the exception of Emotionality where a positive correlation with DB is observed. Overall, for adolescent behaviours, the general picture is one of negative relationships between trait EI and deviancy for males and positive relationships for females, very much in line with the results of Bacon et al (2014; males and females) and Milojević et al (2016; males only). However, while the 
Running head: TRAIT EI AND DEVIANT BEHAVIOUR

positive associations between female $\mathrm{CB}$ and trait EI observed in the adolescent data disappear in emerging adulthood, for males the inverse is apparent - little relationship between $\mathrm{CB}$ and trait EI in adolescence, and negative associations in emerging adulthood. However, reports of adolescent and emerging adult deviance were positively related (females $\mathrm{CB} r=.36, \mathrm{DB} r=.33, p<.001$ in both case; males $\mathrm{CB} r=.21, p=.02$ and $\mathrm{DB} r=.33, p$ $<.001)$

\section{PLEASE INSERT TABLE 2 ABOUT HERE}

In Study 2, we observed markedly different associations than in Study 1. Here, with an older sample, it is the females who show the pattern of negative correlations between trait EI and both types of deviancy. The males now show only one association, a positive correlation between Sociability and both CB and DB.

We conducted linear regression analyses on each of the deviancy measures, with gender, the four trait EI factors and the potential interaction between these as predictors. The interaction variables were calculated as the product of gender $($ coded male $=1$ and female $=$ 0) and each of the trait EI scores. These allowed us to test whether the relationship between trait EI and deviancy differed as function of gender. For adolescent CB and DB and all four trait EI variables, skewness and kurtosis values fell well within the acceptable range of between -2 and +2 suggesting the data are close to normally distributed (West, et al, 1995). Adult scores showed higher skewness and kurtosis values as the reported levels of deviancy are relatively low (as we might expect in a non-forensic sample) resulting a negatively skewed distribution. However, on calculating the regressions, residual scores were found to be normally distributed suggesting the assumptions of regression analysis are not violated. 


\section{Running head: TRAIT EI AND DEVIANT BEHAVIOUR}

Results of the regressions are shown in Table 3. Gender, emotionality and the interaction between these shared independent variance with adolescent $\mathrm{CB}$, reflecting the inverse directional effects for males and females. The model accounted for $9 \%$ variance in this type of behaviour. For DB, the picture is a little different with gender, its interaction with both emotionality and the interaction with self-control the independently significant factors. The model accounted for $13 \%$ variance in DB. For emerging adulthood behaviours, the regression indicated that gender and Emotionality were again the key predictors, both individually and in interaction, with the model accounting for $8 \%$ of emerging adult $\mathrm{CB}$ and $10 \%$ of DB.

In terms of the adult data in Study 2, the model accounts for $19 \%$ variance in CB, with gender and its interaction with sociability independent predictors. For DB, Self-control and the gender * sociability interaction are the only factors to share independent variance with DB, the model accounting for $20 \%$ variance overall.

\section{PLEASE INSERT TABLE 3 ABOUT HERE}

Finally, we made a simple comparison of levels of reported deviancy across the two studies and hence also across the three lifestages. Within Study 1, both males and females reported significantly less of both types of behaviour in emerging adulthood, compared to adolescence: males CB $t(124)=6.10, p<.001$, DB $t(124)=8.36, p<.001$; females CB $t$ $(130)=8.81, p<.001, \mathrm{DB} t(130)=9.94, p<.001$. Comparing these emerging adulthood reports with those for full adulthood in Study 2 however, we observed no significant decline for male participants: $t(240)=.06, \mathrm{p}=.95$ for CB and $t(240)=.75, p=.47$ for DB. Females in Study 2 reported significantly fewer of both types of behaviour in comparison with the 


\section{Running head: TRAIT EI AND DEVIANT BEHAVIOUR}

reports of emerging adulthood in Study $1, t(247)=4.37, p<.001$ for CB and $t(247)=2.79$, $p=.01$ for DB.

\section{Discussion}

These two studies confirm that the relationship between socially deviant behaviours and trait EI is not straightforward. Generally considered a positive attribute, our results present evidence that higher levels of trait EI may actually facilitate both criminal and non-criminal deviant behaviours, especially among younger women and adult males. This research builds on the extant work of Bacon et al (2014) by explicating the aspects of the trait which are most salient in helping to explain adolescent deviance in both males and females. In addition, we present preliminary investigations into how the EI profile of deviant individuals changes as they move through emerging adulthood and into full adulthood, lifestages when they should have normatively desisted from typical adolescent-limited behaviour.

For male participants aged 18-25, our results supported the prediction that deviant behaviours would be negatively associated with the trait EI factor Self-control, reflecting a tendency towards impulsivity, poor emotional regulation and difficulties managing stress. Overall, this is exactly the trait El profile we might expect in antisocial individuals given previous research on measures of similar constructs but measured independently of trait El, such as empathy and self-regulation (e.g. Cohen \& Strayer, 1996; Downey et al, 2010; Jolliffe \& Farrington, 2007). In contrast, for female participants, we predicted a positive association between trait El factors Emotionality and Sociability to support Bacon et al's suggestion that empathy, emotion perception, social skills and the ability to influence other people's feelings are associated with deviant behaviour in young female. Our results fully uphold this prediction. 
In addition, we extended Bacon et al.'s (2014) research to examine more contemporaneous self-reports of deviancy committed within the previous 12 months - during the emerging adulthood lifestage. For males, negative associations between these behaviours and both Sociability and Wellbeing are observed which were not apparent when adolescent deviancy was considered. It would seem that for emerging adult males, deviancy is still associated with impulsivity and poor self-regulation but the males reporting such behaviours are also now less socially skilled, less happy and have lower self-esteem - factors which didn't seem to have significant influence as adolescents. Given the positive correlations between adolescent and emerging adult deviancy in the sample, we can assume that such individuals were also the most antisocial in adolescence.

In Study 2 we found that adult deviancy is related to different trait EI profiles to deviancy in either adolescence or emerging adulthood. For males, impulsivity and poor selfregulation are no longer predictive of deviancy, and instead it is those with strong social skills, assertiveness and the ability to influence others' emotions (i.e. high scorers on Sociability) who appear to be the most antisocial. For adult women, the overall level of deviancy reported was particularly low and correlations suggested a generally negative relationship with trait EI, in contrast to those in Study 1. Female offending has received relatively little research attention compared to that of men, possibly because they are considered to commit less serious offences and are therefore less costly to society, or because they tend to be perceived more as the victims of crime rather than the perpetrators (ChesneyLind \& Shelden, 2014; Schwartz \& Steffensmeier, 2007). However, as Schwartz \& Steffensmeier (2007) discuss, when it comes to less serious offences the gender gap virtually disappears, and, given the nature of our sample, low level offending is presumably what our 


\section{Running head: TRAIT EI AND DEVIANT BEHAVIOUR}

adult females are mainly involved with. As such, examining the nature of the offences committed by these individuals might help to explain the relationship between this behaviour and trait El profile they present. Our self-report questionnaire was designed primarily to elicit information about offending prevalence, and in presenting a fairly wide range of behaviours within a relatively short measure does not lend itself well to a detailed examination of their typologies. However, deviance in the older sample was associated with low trait El, rather than high, so this is likely a group with little emotional awareness about the impact of their actions. As such we suggest that this may not be continuation of the intentional manipulativeness reported in adolescent girls, but a very different type of behaviour altogether. Overall a more detailed exploration of the relationships between trait EI and offending/deviancy in adult women is required, employing more sensitive measures of types of crime and strain experiences.

These differences between genders and over the trajectory from adolescence into adulthood are intriguing, and presumably reflect the effects of socialisation as well as maturation. For instance, much adult male socially deviant behaviour is sporadic, attributable to contextual peer pressure and often co-occurs with acute alcohol consumption (Rolfe et al., 2006; Wells, Graham, \& West, 2000). There is evidence that supposedly adolescence-limited male offenders continue to drink heavily, use drugs, get into fights and sometimes commit criminal acts into adulthood (Nagin, Farrington \& Moffitt, 1995). Assertiveness in trait El terms (as reflected in the Sociability factor) is defined as being forthright and willing to stand up for ones' rights and in the above context, this behaviour may lead to conflict given that anger and a sense of injustice in males is known to relate to other-oriented physical aggression (Agnew, 2007). Emotional management and understanding (also reflected in the Sociability factor) have been found to increase the tendency to engage in confrontational 


\section{Running head: TRAIT EI AND DEVIANT BEHAVIOUR}

aggression among individuals who perceive this to be an effective and justified strategy for dealing with interpersonal conflict (Moeller \& Kwantes, 2015). A key factor which differentiates men who desist from deviancy after adolescence and those who continue is stability in daily life. This tends to increase with age and the establishment of stable living arrangements, work and personal relationships (Kerr et al, 2011; Laub, Nagin \& Sampson, 1998; Sampson, Laub \& Wimer, 2006). We did not collect data on employment or relationship status, but it likely that similar factors account for the decreasing levels of deviancy reported by males from adolescence to emerging adulthood given that participants in Study 1 were students and therefore presumably fairly settled in academic life.

Women who behave deviantly in adulthood are those who are low in emotional understanding and regulation, high in impulsivity and who find it difficult to deal with stress in their lives. They may also have little empathy and understanding of emotions. It is easy to see how this might be further linked with low Wellbeing - they are unhappy, least optimistic about their future and lack self-esteem. This profile is fairly typical of women who offend, often in the context of a range of strains such as chaotic lifestyle, poverty and/or destructive personal relationships (Agnew, 2007, 2012; Cauffman, Farruggia, and Goldweber, 2008; Hollin \& Palmer, 2006; Odgers \& Moretti, 2002). In addition, while a link between assuming adult responsibilities and desisting from crime is frequently reported for males, the effect is less common among females (Sampson et al, 2006). In fact, for females, marriage to an antisocial mate can reinforce adolescent deviancy throughout adulthood, often in the form of aggressive behaviour within the home and against family members (Agnew, 2007; Cauffman, 2008) 
Running head: TRAIT EI AND DEVIANT BEHAVIOUR

The present studies are not without limitations, not least of which are those inherent in self-report methods and our analysis is necessarily dependent on participants' perceptions of their behaviour as antisocial or not. Those individuals who are more open to perceive themselves as "deviant" might also score higher on trait EI while those who actually commit crimes may not be so open or self-aware. Furthermore, we present only a preliminary study of the older age group and any interpretations are limited by the cross-sectional nature of the research. As we have not followed the same individuals longitudinally through adolescence and into adulthood we cannot draw any definitive conclusions about their criminogenic development. Our age cut off-point for study 1 (25 years) was chosen partly to replicate the sample used by Bacon et al (2014), and also reflect the age range typified for emerging adulthood. However, in effect, many younger participants reporting deviant behaviour within the last 12 months may still have emotionally been in adolescence. Retrospective reports of adolescence, although restively recent in lifespan terms, might also have been subject to memory distortions and as possibly retrospective social desirability bias. Again, this highlights the need for longitudinal work to overcome these shortcomings as well as consideration of trait EI in convicted samples, extending the extant work of Milojevic et al (2016) to female offenders.

A further question is the extent to which our participants are typical of those whose antisocial behaviours are most problematic for society. Study 1 participants were students, and those in Study 2 were fairly well educated individuals. As such, it could be argued that our samples are not representative of the overall population, or of the more deviant sectors of society. We also lack information on family and social relationships, employment, socioeconomic and mental health status, factors known to contribute to the aetiology of both juvenile delinquency and adult offending. In terms of trait EI, wellbeing and sociability for 


\section{Running head: TRAIT EI AND DEVIANT BEHAVIOUR}

instance could have different meanings for socially deprived/low educated persons compared to those in more affluent and educated circumstances. Furthermore, it is notable that other measures of Emotional Intelligence, for instance those which assess the construct from an ability perspective, may yield differing results.

While our older participants reported lower rates of deviant behaviours, in keeping with Moffitt's $(1993,2006)$ theory of adolescent limited behaviour, those who did report adult it may not be the life-course persistent (LCP) offenders she also specified. LCP offenders tend to display early childhood conduct disorder, commit serious offences and often experience neurological deficits which limit their socio-emotional development. Evidence suggests that children with the highest initial levels of developmentally-early conduct problems at school entry are more likely to show persistent or worsening problems over time and are less likely to desist after adolescence (Brame et al., 2001; Nagin \& Tremblay, 1999). We have no data to refute or support these possibilities with regard to our participants however, given the nature of our sample (i.e. non-incarcerated, never convicted, happy to complete online questionnaires and either university students or at a comparable educational level) it seems unlikely that they fit this typology. Furthermore, while the trait El profile of our younger offenders complement characteristics that Lahey and Waldman (2003)'s antisocial propensity theory suggests predispose to criminal behaviour (daring, negative Emotionality and, in the case of females participants, prosociality), these factors are less apparent in our adult sample. We suggest that the majority of our participants took part in what can been termed normative deviancy in adolescence and then desisted.

Nonetheless, the present study provides some new and important insights onto the relationship between socially deviant behaviours and trait El. We elucidate the results of 
Running head: TRAIT EI AND DEVIANT BEHAVIOUR

previously published work on adolescent offending, and extend the investigation to adults who are still reporting deviant and who present with different trait El profiles to adolescents. In particular, we have identified a group of adult women with low trait El levels who report acting in an antisocial fashion. Their trait El profile suggests that poor social relationships may form a bedrock for their deviant behaviour, and it is well-documented that the roots of problem behaviour in females are frequently embedded in their relationships, particularly with men (Cauffman, et al., 2008; Odgers \& Moretti, 2002) and may be further linked to low levels of social support (Goldweber et al, 2009). Trait EI training can be effective in increasing emotional competence and improving psychological and physical wellbeing, social relationships, and employability (Nelis, et al, 2011). Understanding the intrapersonal, as well as social and instrumental, factors which underpin individual differences in antisocial behaviour can allow us to provide effective interventions which address the differing criminogenic needs of men and women. 
Running head: TRAIT EI AND DEVIANT BEHAVIOUR

\section{References}

Agnew, R. (2007). Pressured into Crime: An Overview of General Strain Theory. Oxford: Oxford University Press.

Agnew, R. (2012). Reflection on "A Revised Strain Theory of Delinquency". Social Forces, 91, 33-38. doi: http://dx.doi.org/10.1093/sf/sos117

Archer, J. (2004). Sex differences in aggression in real-world settings: A meta-analytic review. Review of General Psychology, 8(4), 291-322. doi: http://dx.doi.org/10.1037/1089-2680.8.4.291

Arnett, J.J. (2000). Emerging Adulthood: A Theory of Development From the Late Teens through the Twenties. American Psychologist, 55, 469-480. doi: http://dx.doi.org/10.1037/0003-066X.55.5.469

Austin, E. J., Saklofske, D. H., \& Egan, V. (2005). Personality, well-being and health correlates of trait emotional intelligence. Personality and Individual Differences, 38(3), 547-558. doi: http://dx.doi.org/10.1016/j.paid.2004.05.009

Austin, E. J., \& O’Donnell, M. M. (2013). Development and preliminary validation of a scale to assess managing the emotions of others. Personality and Individual Differences, 55, 834-839. doi: http://dx.doi.org/10.1016/j.paid.2013.07.005 
Running head: TRAIT EI AND DEVIANT BEHAVIOUR

Bacon, A.M., Burak, H. \& Rann, J. (2014). Sex differences in the relationship between sensation seeking, trait emotional intelligence and delinquent behaviour. The Journal of Forensic Psychiatry \& Psychology, 25, 673-683. doi:

http://dx.doi.org/10.1080/14789949.2014.943796

Bacon, A.M \& Regan, L. (2016). Manipulative relational behaviour and delinquency: sex differences and links with emotional intelligence. The Journal of Forensic Psychiatry \& Psychology, 27, 331-348. doi: $\underline{10.1080 / 14789949.2015 .1134625}$

Björkqvist, K. (1994). Sex differences in physical, verbal, and indirect aggression: a review of recent research. Sex Roles, 30(3-4), 177-188. doi: http://dx.doi.org/10.1007/BF01420988

Brackett, M.A., Mayer, J.D., \& Warner, R.M. (2004). Emotional intelligence and its relation to everyday behaviour. Personality and Individual Differences, 36, 1387-1402. doi: http://dx.doi.org/10.1016/S0191-8869(03)00236-8

Brame, B., Nagin, D. S., Tremblay, R. E. (2001). Developmental trajectories of physical aggression from school entry to late adolescence. Journal of Child Psychology and Psychiatry, 42, 503-512. doi: http://dx.doi.org/10.1111/1469-7610.00744

Cauffman, E. (2008). Understanding the female offender. The Future of Children, 18(2),119142. doi: http://dx.doi.org/10.1353/foc. 0.0015 
Running head: TRAIT EI AND DEVIANT BEHAVIOUR

Cauffman, E., Farruggia, S.P. \& Goldweber, A. (2008). Bad Boys or Poor Parents: Relations to Female Juvenile Delinquency. Journal of Research on Adolescence, 18, 699-712. doi: doi: http://dx.doi.org/10.1111/j.1532-7795.2008.00577.x

Chesney-Lind, M., \& Shelden, R.G. (2014). Girls, Delinquency, and Juvenile Justice (4 $^{\text {th }}$ ed.). Belmont, CA: Wadsworth.

Christie, R., \& Geis, F. (1970). Studies in Machiavellianism. New York, NY: Academic Press.

Cohen, D. \& Strayer, J. (1996). Empathy in conduct-disordered and comparison youth Developmental Psychology, 32, 988-998. doi: http://dx.doi.org/10.1037/0012$\underline{1649.32 .6 .988}$

Downey, L.A., Johnston, P.J., Hansen, K., Birney, J., \& Stough, C. (2010). Investigating the mediating effects of emotional intelligence and coping on problem behaviours in adolescents. Australian Journal of Psychology, 62, 20-29. doi: http://dx.doi.org/10.1080/00049530903312873.

Eisenberg, N. et al (1996). The relations of regulation and emotionality to problem behavior in elementary school children. Development and Psychopathology, 8, 141-162. doi: https://doi.org/10.1017/S095457940000701X

Fonagy, P., Target, M., Steele, M., Steele, H., Leigh, T., Levinson, A., \& Kennedy, R. (1997). Morality, disruptive behavior, borderline personality disorder, crime and their 
Running head: TRAIT EI AND DEVIANT BEHAVIOUR

relationship to security of attachment. In L. Atkinson \& K. J. Zucker (Eds.), Attachment and psychopathology (pp. 223-274). New York: Guilford Press.

Goldweber, A., Broidy, L.M. \& Cauffman, E. (2009). Interdisciplinary Perspectives on Persistent Female Offending: A Review of Theory and Research. In J. Savage (Ed.). The Development of Persistent Criminality (pp. 205-230) Oxford: Oxford University Press.

Gomà-i-Freixanet, M. (1995). Prosocial and antisocial aspects of personality. Personality and Individual Differences, 19, 125-134. doi: http://dx.doi.org/10.1016/0191-8869(95)00037-7

Grieve, R. \& Panebianco, L. (2013). Assessing the role of aggression, empathy, and selfserving cognitive distortions in trait emotional manipulation. Australian Journal of Psychology, 65, 79-88. doi: http://dx.doi.org/10.1111/j.1742-9536.2012.00059.x

Gugliandolo, M. C., Costa, S., Cuzzocrea, F., \& Larcan, R. (2015). Trait emotional intelligence as mediator between psychological control and behaviour problems. Journal of Child and Family Studies, 24, 2290-2300. http://dx.doi.org/10.1007/s10826-014-0032-3

Hayes, J.M., \& Reilly, G.O. (2013). Psychiatric disorder, IQ, and emotional intelligence among adolescent detainees: A comparative study. Legal and Criminological Psychology, 18(1), 30-47. doi: http://dx.doi.org/10.1111/j.2044-8333.2011.02027.x

Hollin, C.R. \& Palmer. M.J. (2006). Criminogenic need and women offenders: A critique of the literature. Legal and Criminological Psychology, 11, 179-195. doi: http://dx.doi.org/10.1348/135532505X57991 
Running head: TRAIT EI AND DEVIANT BEHAVIOUR

Home Office (2014). Anti-social Behaviour, Crime and Policing Act: anti-social behaviour. https://www.gov.uk/government/publications/anti-social-behaviour-crime-and-policingbill-anti-social-behaviour. Accessed on 06/10/2017

Jolliffe, D., \& Farrington, D. P. (2007). Examining the relationship between low empathy and self-reported offending. Legal and Criminological Psychology, 12(2), 265-286. doi: $\underline{10.1348 / 135532506 \times 147413}$

Jones, D.N., \& Paulhus, D.L. (2011). The role of impulsivity in the Dark Triad of personality. Personality and Individual Differences, 51, 679-682. doi: http://dx.doi.org/10.1016/j.paid.2011.04.011

Kerr, D. C., Capaldi, D. M. Owen, L. D., \& Pears, K. (2011). Changes in at-risk American men's crime and substance use trajectories following fatherhood. Journal of Marriage and Family, 73, 1101-1116. doi: http://dx.doi.org/10.1111/j.1741-3737.2011.00864.x

Kokkinos, C. M., \& Kipritsi, E. (2012). The relationship between bullying, victimization, trait emotional intelligence, self-efficacy and empathy among preadolescents. Social Psychology of Education, 15, 41-58.

Lahey, B.B. \& Waldman, I.D. (2003). A developmental propensity model of the origins of conduct problems during childhood and adolescence. In B. B. Lahey, T. E. Moffitt, \& A. Caspi (Eds.). Causes of Conduct Disorder and Juvenile Delinquency (pp. 76-117). New York: Guilford Press. 
Running head: TRAIT EI AND DEVIANT BEHAVIOUR

Laub, J., Nagin, D., \& Sampson, R. (1998). Trajectories of Change in Criminal Offending: Good Marriages and the Desistance Process. American Sociological Review, 63, 225-238. doi: http://dx.doi.org/10.2307/2657324

Marshall, L.E. \& Marshall, W.L. (2011). Empathy and antisocial behaviour. The Journal of Forensic Psychiatry \& Psychology, 22, 742-759. doi: http://dx.doi.org/10.1080/14789949.2011.617544

Mavroveli, S., Petrides, K.V., Rieffe, C. \& Bakker, F. (2007). Trait emotional intelligence, psychological well-being and peer-rated social competence in adolescence. British Journal of Developmental Psychology, 25(2), 263-275. doi:

http://dx.doi.org/10.1348/026151006X118577

Milojević, S., \& Dimitrijević, A. (2014). Empathic capacity of delinquent convicted minors. Psihologija, 47(1), 65-79. http://dx.doi.org/10.2298/PSI1401065M

Milojević, S., Dimitrijević, A. A., Marjanović, Z. J., \& Dimitrijević, A. (2016). Bad past, gloomy future: The trait emotional intelligence profile of juvenile offenders. Personality and Individual Differences, 94, 295-298.

Moeller,C.,\& Kwantes,C.T.(2015).Too much of a good thing? Emotional intelligence and interpersonal conflict behaviors. Journal of Social Psychology, 155, 314-324. doi: http://dx.doi.org/10.1080/00224545.2015.1007029 
Running head: TRAIT EI AND DEVIANT BEHAVIOUR

Moffitt, T. E. (1993). 'Life-course persistent' and 'adolescent-limited' antisocial behaviour: A developmental taxonomy. Psychological Review, 100, 674-701. doi: http://dx.doi.org/10.1037/0033-295X.100.4.674

Moffitt, T.E. (2006). Life-course persistent versus adolescent-limited antisocial behaviour. In D. Cicchetti \& Cohen, D.J. (Ed.). Developmental psychopathology, Vol 3: Risk, disorder, and adaptation (2nd ed.), (pp. 570-598). Hoboken, NJ,: Wiley \& Sons.

Moffitt, T.E., Arseneault, L., Belsky, D. et al (2011). A gradient of childhood self-control predicts health, wealth, and public safety. PANAS, 108, 2693-2698, doi: http://dx.doi.org/10.1073/pnas.1010076108

Nagin, D.S., Farrington, D.P. \& Moffitt, T.E. (1995). Life-course trajectories of different types of offenders. Criminology, 33(1), 111-139. doi: http://dx.doi.org/10.1111/j.17459125.1995.tb01173.x

Nagin, D. S., \& Tremblay, R. (1999). Trajectories of boys' physical aggression, opposition, and hyperactivity on the path to physically violent and non-violent juvenile delinquency. Child Development, 70, 1181-1196.

Nelis, D., Kotsou, I., Quoidbach, J., Hansenne, M., Weytens, F., Dupuis, P., et al. (2011). Increasing emotional competence improves psychological and physical well-being, social relationships, and employability. Emotion, 11(2), 354-366. doi: http://dx.doi.org/10.1037/a0021554 
Running head: TRAIT EI AND DEVIANT BEHAVIOUR

O’Boyle, E.H., Humphrey, R.H., Pollack, J.M., Hawver, T.H., \& Story, P.A. (2011). The relation between emotional intelligence and job performance: A meta-analysis. Journal of Organizational Behavior, 32, 788-818. doi: http://dx.doi.org/10.1002/job.714

Odgers, C. L., \& Moretti, M. M. (2002). Aggressive and antisocial girls: Research update and challenges. International Journal of Forensic Mental Health, 1, 103-119. doi: http://dx.doi.org/10.1080/14999013.2002.10471166

Österman, K., Björkqvist, K., Lagerspetz, K.M.J., Kaukiainen, A., Landau, S.F., Fraczek, A. \& Caprara, G.V. (1998) Crosscultural evidence of female indirect aggression. Aggressive Behavior. 24, 1-8. doi: http://dx.doi.org/10.1002/(SICI)1098-2337

Pérez-González, J. C., \& Sanchez-Ruiz, M. J. (2014). Trait emotional intelligence anchored within the Big Five, Big Two and Big One frameworks. Personality and Individual Differences, 65, 53-58. https://doi.org/10.1016/j.paid.2014.01.021

Petrides, K. V. (2009). Technical Manual for the Trait Emotional Intelligence Questionnaires (TEIQue). London: London Psychometric Laboratory.

Petrides, K. V. \& Furnham, A. (2003). Trait emotional intelligence: Behavioural validation in two studies of emotion recognition and reactivity to mood induction. European Journal of Personality, 17(1), 39-57. doi: http://dx.doi.org/10.1002/per.466

Petrides, K.V., Frederickson, N., \& Furnham, A. (2004). The role of trait emotional intelligence in academic performance and deviant behavior at school. Personality and 
Running head: TRAIT EI AND DEVIANT BEHAVIOUR

Individual Differences, 36, 277-293. doi: http://dx.doi.org/10.1016/S01918869(03)00084-9

Petrides, K. V., Pita, R., \& Kokkinaki, F. (2007). The location of trait emotional intelligence in personality factor space. British Journal of Psychology, 98(2), 273-289. doi: http://dx.doi.org/10.1348/000712606X120618

Petrides K. V., Mikolajczak M., Mavroveli S., Sanchez-Ruiz M. J., Furnham A., PerezGonzales J. C. (2016). Developments in trait emotional intelligence research. Emotion Review, 8 (4), 335-341. doi: https://doi.org/10.1177/1754073916650493

Piquero, A. R., Brame, R., Mazerolle, P., \& Haapanen, R. (2002). Crime in emerging adulthood. Criminology, 40, 137-169. doi: http://dx.doi.org/10.1111/j.17459125.2002.tb00952.x

Rolfe, A., Dalton, S. Krishnan, M., Orford, J., Mehdikhani, M., Cawley, J. \& Ferrins-Brown, M. (2006). Alcohol, gender, aggression and violence: findings from the Birmingham untreated Heavy Drinkers Project. Journal of Substance Use, 11(5), 343-358. doi: http://dx.doi.org/10.1080/14659890600677487

Romero, E., Luengo, M.A., \& Sobral, J. (2001). Personality and antisocial behaviour: Study of temperamental dimensions. Personality and Individual Differences, 31, 329-348. doi: http://dx.doi.org/10.1016/S0191-8869(00)00139-2 
Running head: TRAIT EI AND DEVIANT BEHAVIOUR

Rutter, M. (2003). Commentary: Causal processes leading to antisocial behaviour. Developmental Psychology, 39, 372-378. http://dx.doi.org/10.1037/0012-1649.39.2.372

Sampson, R.J. \& J. H. Laub, J.H. \& Wimer, C. (2006). Does Marriage Reduce Crime? A Counter-Factual Approach to Within-Individual Causal Effects. Criminology, 44, 465508. doi: doi: http://dx.doi.org/10.1111/j.1745-9125.2006.00055.x

Schutte, N.S., Malouff, J.M., Thorsteinsson, E.B., Bhullar, N., \& Rooke, S.R. (2007). A meta-analytic investigation of the relationship between emotional intelligence and health. Personality and Individual Differences, 42, 921-933. doi: http://dx.doi.org/10.1016/j.paid.2006.09.003

Schwartz, J. \& Steffensmeier, D. (2007). The nature of female offending: patterns and explanations. In Zaplin, R. (Ed.). Female Offenders: Critical Perspectives and Effective Interventions ( $2^{\text {nd }}$ ed.) pp. 43-75. Boston, MA: Jones and Bartlett

Viding, E., Simmonds, E. Petrides, K.V. \& Frederickson, N. (2009). The contribution of callous-unemotional traits and conduct problems to bullying in early adolescence. Journal of Child Psychology and Psychiatry, 50(4), 471-481. doi: http://dx.doi.org/10.1111/j.1469-7610.2008.02012.x

Warwick, J. \& Nettelbeck, T. (2004). Emotional intelligence is...? Personality and Individual Differences, 37, 1091-1100. doi: http://dx.doi.org/10.1016/j.paid.2003.12.003 
Running head: TRAIT EI AND DEVIANT BEHAVIOUR

Wells, S., Graham, K. \& West, P. (2000). Alcohol-related aggression in the general population. Journal of Studies on Alcohol, 61(4), 626-632. http://dx.doi.org/10.15288/jsa.2000.61.626

West, S.G., Finch, J.F. \& Curran, P.J. (1995). Structural equation models with nonnormal variables: problems and remedies. In R.H. Hoyle (Ed.). Structural Equation Modeling: Concepts, Issues and Applications (pp. 56-75). Newbery Park, CA: Sage.

Wong, C.-S., \& Law, K.S. (2002). The effects of leader and follower emotional intelligence on performance and attitude: An exploratory study. The Leadership Quarterly, 13, 243274. doi: http://dx.doi.org/10.1016/S1048-9843(02)00099-1

Zeidner, M., Matthews, G., \& Roberts, R. (2009). What We Know About Emotional Intelligence. How it Affects Learning, Work, Relationships, and Our Mental Health. Cambridge: MIT Press.

Zeidner, M., Matthews, G., \& Roberts, R. D. (2012). Emotional intelligence, health, and well-being nexus: What we have learned and what we have missed? Applied Psychology, Health and Well-Being, 4, 1-30. doi: 10.1111/j.1758-0854.2011.01062.x 
Running head: TRAIT EI AND DEVIANT BEHAVIOUR

Table 1. Descriptive statistics for male and female participants in Studies 1 and 2.

\begin{tabular}{|c|c|c|c|c|c|c|c|c|c|c|c|}
\hline & & \multicolumn{6}{|c|}{ Socially deviant behaviours } & \multicolumn{4}{|c|}{ Trait EI factors } \\
\hline & & \multirow[b]{2}{*}{ Deviant } & \multicolumn{2}{|c|}{$\begin{array}{l}\text { Adolescent } \\
\text { (aged 12-18) }\end{array}$} & \multicolumn{3}{|c|}{$\begin{array}{l}\text { Emerging adult/adult } \\
\text { (within } 12 \text { months) }\end{array}$} & \multirow[b]{2}{*}{ Wellbeing } & \multirow[b]{2}{*}{ Self-control } & \multirow[b]{2}{*}{ Emotionality } & \multirow[b]{2}{*}{ Sociability } \\
\hline & & & Criminal & Total & Deviant & Criminal & Total & & & & \\
\hline \multicolumn{12}{|l|}{ Study 1} \\
\hline \multirow[t]{2}{*}{ Males } & Mean & 4.30 & 3.90 & 8.20 & 1.80 & 1.71 & 3.51 & 4.50 & 4.24 & 4.47 & 4.42 \\
\hline & SD & 3.24 & 3.84 & 5.92 & 2.11 & 2.18 & 3.33 & 1.07 & .76 & .73 & .79 \\
\hline \multirow[t]{2}{*}{ Females } & Mean & 4.78 & 3.83 & 8.61 & 1.64 & 1.41 & 3.05 & 4.53 & 3.99 & 4.82 & 4.34 \\
\hline & $\mathrm{SD}$ & 3.68 & 3.33 & 6.31 & 2.23 & 1.67 & 3.40 & 1.05 & .75 & .79 & .73 \\
\hline \multicolumn{12}{|l|}{ Study 2} \\
\hline \multirow[t]{2}{*}{ Males } & Mean & - & - & - & 2.05 & 1.69 & 3.74 & 4.43 & 4.42 & 4.44 & 4.33 \\
\hline & SD & - & - & - & 2.83 & 3.02 & 5.07 & 1.09 & .74 & .74 & .89 \\
\hline \multirow[t]{2}{*}{ Females } & Mean & - & - & - & .98 & .63 & 1.61 & 4.65 & 4.25 & 4.91 & 4.33 \\
\hline & SD & - & - & - & 1.33 & 1.04 & 2.05 & 1.03 & .91 & .87 & .92 \\
\hline
\end{tabular}


Table 2. Correlations between levels of reported criminal behaviour (CB), deviant behaviour (DB) and trait EI measures in Studies 1 and 2.

\begin{tabular}{|c|c|c|c|c|}
\hline \multirow[t]{2}{*}{ Study 1} & \multicolumn{2}{|c|}{ Adolescent CB } & \multicolumn{2}{|c|}{ Adolescent DB } \\
\hline & Male & Female & Male & Female \\
\hline Wellbeing & -.03 & .14 & $-.19^{*}$ & .11 \\
\hline Self-control & -.10 & .09 & $-.27 * *$ & $.20 *$ \\
\hline Emotionality & -.11 & $.28 * *$ & $-.20 *$ & $.24 * *$ \\
\hline Sociability & .12 & $.26 * *$ & .07 & $.25^{* *}$ \\
\hline \multirow[t]{2}{*}{ Study 1} & \multicolumn{2}{|c|}{ Emerging adult $\mathrm{CB}$} & \multicolumn{2}{|c|}{ Emerging adult DB } \\
\hline & Male & Female & Male & Female \\
\hline Wellbeing & $-.22 *$ & -.01 & $-.19^{*}$ & .09 \\
\hline Self-control & $-.19 *$ & -.11 & $-.29 * *$ & .05 \\
\hline Emotionality & $-.25 * *$ & -.14 & $-.26 * *$ & $.28 * *$ \\
\hline Sociability & $-.18 *$ & .15 & -.15 & .10 \\
\hline \multirow[t]{2}{*}{ Study2 } & \multicolumn{2}{|c|}{ Adult CB } & \multicolumn{2}{|c|}{ Adult DB } \\
\hline & Male & Females & Males & Females \\
\hline Wellbeing & .21 & $-.35 * *$ & .10 & $-.23^{*}$ \\
\hline Self-control & .16 & $-.33 * *$ & -.04 & $-.37 * *$ \\
\hline Emotionality & .16 & $-.31 * *$ & .13 & $-.18^{*}$ \\
\hline Sociability & $.33 * *$ & -.04 & $.34 * *$ & -.01 \\
\hline
\end{tabular}


Table 3. Results of linear regression analyses on criminal and deviant behaviours reported in adolescence and emerging adulthood (Study 1) and adulthood (Study 2).

\begin{tabular}{|c|c|c|c|c|c|c|c|c|c|c|}
\hline \multirow[b]{3}{*}{ Study 1: Adolescent } & \multicolumn{5}{|c|}{ Criminal behaviour } & \multicolumn{5}{|c|}{ Deviant behaviour } \\
\hline & \multicolumn{5}{|c|}{$95 \% \mathrm{CI}$} & \multirow[b]{2}{*}{$\beta$} & \multirow[b]{2}{*}{$t$} & \multirow[b]{2}{*}{$p$. } & \multicolumn{2}{|c|}{$95 \% \mathrm{CI}$} \\
\hline & $\beta$ & $t$ & $p$. & Lower & Upper & & & & Lower & Upper \\
\hline Gender & 1.17 & 2.58 & .01 & 1.98 & 14.80 & 1.68 & 3.77 & $<.001$ & 5.57 & 17.75 \\
\hline Wellbeing & -.05 & -.41 & .69 & -.97 & .64 & -.17 & -1.41 & .16 & -1.31 & .22 \\
\hline Self-control & -.05 & -.45 & .66 & -1.22 & .77 & .15 & 1.46 & .15 & -.25 & 1.64 \\
\hline Emotionality & .23 & 1.97 & .05 & .002 & 2.07 & .19 & 1.71 & .09 & -.13 & 1.84 \\
\hline Sociability & .17 & 1.61 & .11 & -.18 & 1.76 & .19 & 1.87 & .06 & -.05 & 1.80 \\
\hline Gender*wellbeing & .18 & .44 & .66 & -.92 & 1.45 & .15 & .39 & .70 & -.90 & 1.35 \\
\hline Gender*self-control & -.20 & -.44 & .66 & -1.78 & 1.13 & -.98 & -2.22 & .03 & -2.933 & -.17 \\
\hline Gender*emotionality & -1.54 & -3.08 & .002 & -3.95 & -.87 & -1.34 & -2.73 & .01 & -3.50 & -.57 \\
\hline Gender*sociability & .43 & .94 & .35 & -.74 & 2.08 & .38 & .86 & .40 & -.76 & 1.92 \\
\hline \multicolumn{11}{|c|}{ Study 1: Emerging adulthood } \\
\hline Gender & 1.38 & 3.02 & .003 & 1.87 & 8.85 & 1.86 & 4.12 & $<.001$ & 4.20 & 11.91 \\
\hline Wellbeing & -.06 & -.53 & .60 & -.56 & .32 & -.10 & -.87 & .39 & -.70 & .27 \\
\hline Self-control & -.19 & -1.72 & .09 & -1.01 & .07 & -.06 & -.51 & .61 & -.75 & .44 \\
\hline Emotionality & .17 & 1.47 & .14 & -.14 & .98 & .38 & 3.33 & .001 & .43 & 1.67 \\
\hline Sociability & .14 & 1.34 & .18 & -.17 & .89 & -.03 & -.29 & .77 & -.67 & .50 \\
\hline Gender*wellbeing & -.03 & -.07 & .94 & -.66 & .62 & .44 & 1.12 & .26 & -.31 & 1.12 \\
\hline Gender*self-control & .33 & .73 & .46 & -.50 & 1.08 & -.58 & -1.30 & .19 & -1.45 & .29 \\
\hline Gender*emotionality & -1.11 & -2.20 & .03 & -1.78 & -.10 & -1.76 & -3.53 & $<.001$ & -2.59 & -.73 \\
\hline Gender*sociability & -.47 & -1.04 & .30 & -1.17 & .37 & .13 & .30 & .76 & -.72 & .98 \\
\hline \multicolumn{11}{|l|}{ Study 2: Adult } \\
\hline Gender & -1.30 & -2.92 & .004 & -9.51 & -1.84 & -.81 & -1.82 & .07 & -7.28 & .29 \\
\hline Wellbeing & -.10 & -.68 & .49 & -.76 & .37 & .01 & .10 & .92 & -.53 & .59 \\
\hline Self-control & -.08 & -.71 & .47 & -.71 & .34 & -.22 & -2.03 & .04 & -1.05 & -.02 \\
\hline Emotionality & -.09 & -.81 & .42 & -.82 & .34 & -.06 & -.50 & .62 & -.72 & .43 \\
\hline Sociability & .09 & .89 & .38 & -.25 & .67 & .07 & .75 & .46 & -.28 & .63 \\
\hline Gender*wellbeing & .04 & .09 & .93 & -.80 & .87 & -.33 & -.74 & .46 & 1.13 & .51 \\
\hline Gender*self-control & .72 & 1.53 & .13 & -.20 & 1.57 & .21 & .46 & .65 & -.67 & 1.08 \\
\hline Gender*emotionality & -.50 & -.91 & .36 & -1.52 & .56 & -.27 & -.50 & .61 & -1.29 & .77 \\
\hline Gender*sociability & 1.31 & 2.83 & .01 & .39 & 2.17 & 1.49 & 3.23 & .001 & .56 & 2.32 \\
\hline
\end{tabular}


Running head: TRAIT EI AND DEVIANT BEHAVIOUR

Appendix: Antisocial behaviour self-report questionnaire. Class indicates the classification of each item as either Criminal (CB) or Deviant (DB) behaviours.

\begin{tabular}{lll}
\hline Item Behaviour & Class
\end{tabular}

$1 \quad$ Intentionally damaged someone else's or public property, including by graffiti? $\quad$ CB

2 Made fun of someone because of their race, disability or looks? DB

3 Deliberately excluded someone socially to hurt or embarrass them? DB

$4 \quad$ Bought something you knew was stolen? $\quad$ CB

$5 \quad$ Set fire to a building? $\quad$ CB

6 Pretended to like someone in order to get something you wanted? DB

$7 \quad$ Physically attacked/ beat someone up just for the hell of it? CB

$8 \quad$ Made fun of the way someone dresses? $\quad$ DB

$9 \quad$ Skipped school when you should have been there? $\quad$ CB

10 Told lies about someone to make them look bad? DB

11 Taken something small (worth less than $£ 5$ ) from a shop without paying for it? CB

12 Let off fireworks in the street? $\quad$ CB

13 Made threats towards another individual? $\quad$ CB

14 Said nasty or untrue things behind another person's back? DB

15 Been physically violent towards someone? $\quad \mathrm{CB}$

16 Trolled someone online to provoke fear or to upset them? DB

17 Made a prank phone call for fun? $\quad$ DB

18 Regularly been drunk before the age of 16 ?

19 Posted something on a social networking site with the purpose of upsetting DB another person?

20 Verbally abused someone you did not know, e.g on the street? DB 
Running head: TRAIT EI AND DEVIANT BEHAVIOUR

21 Verbally bullied someone you knew/called them names? DB

22 Taken something worth over $£ 100$ from a shop without paying for it? CB

23 Bullied a peer physically on a regular basis (hit them, pushed them around)? CB

24 Deliberately hurt someone's feelings? DB

25 Cheated in a test or exam? DB

26 Had sex under age 16? CB

27 Had a complaint made against you for noise pollution? E.g. playing music too DB loud.

28 Started a nasty or untrue rumour about someone? DB

29 Been asked to move on by the police for being too loud or rowdy? CB

30 Carried a weapon in a public place? $\quad$ CB

$31 \quad$ Smoked marijuana? $\quad$ CB

32 Stolen something from someone you know? CB

33 Posted upsetting or embarrassing images of someone else online without their DB permission?

34 Taken class A drugs? (e.g. heroin) $\quad$ CB

35 Taken a vehicle belonging to someone else without their knowledge or $\quad$ CB permission? 